\title{
Physical Appearance Anxiety and Social Relations
}

\author{
Jerald C. Moneva \\ Department of Education-Mandaue City Division \\ Mandaue City, Cebu, Philippines \\ Tel: +63908-927-3038Ｅ-mail: Freezingfire1979@gmail.com \\ Justine Gay R. Geñorga \\ Jagobiao National High School \\ Jagobiao, Mandaue City, Cebu, Philippines \\ Tel: +63915-069-8561Ｅ-mail: justinerocel@gmail.com
}

Eugenia M. Solon

Department of Education Division of Cebu Province

Cang- Oyao Bitoon, Daanbantayan, Cebu, Philippines

Tel: +63917-100-7411_E-mail: eugeniasolon5@gmail.com

Received: Jan. 3, 2020 Accepted: Jan. 30, 2020 Published: Feb. 27, 2020

doi:10.5296/ijssr.v8i1.16564 URL: http://dx.doi.org/10.5296/ijssr.v8i1.16564

\begin{abstract}
Students who are afraid of being judged negatively are experience of an anxiety which is called physical appearance anxiety. Social relations refer the relationship between two or more individuals through communication. Students have higher to encounter physical appearance anxiety towards social relations. This study was conducted in senior high school, in Mandaue City, Cebu Philippines. This research design used a descriptive-correlation to assess and to know the students physical appearance anxiety towards social relations using the rating scale researcher made questionnaire among grade 11 and 12 Senior High School student. Moreover, the quantitative data were analyzed through a weighted mean and processed by using a chi-square. It reveals that when a student experience physical appearance anxiety can affects in their social relations. There is a significant association between physical appearance anxiety regards with social relations. This implies that physical
\end{abstract}




\section{Macrothink

appearance anxiety impacts social relations of senior high school students. Hence, the students are expected to face the consequences of physical appearance anxiety positively to cope up the negative impact of anxiety in physical appearance. The researcher recommended that the teachers may guide and help the students in facing anxiety in body image and looks and anti-bullying measures be observed.

Keywords: Anxiety, Physical appearance anxiety, Social relations 


\section{Introduction}

Physical appearance anxiety refers an anxiety feel a dread of negative evaluation of its looks and body image by the people. Meanwhile, social relations mean the relationship between two or more people through communications.

Researchers believe that most of the people today judged by their physical appearance such as their face, hair, nose, color of the skin, height, body weight height and quality of clothing. Studying physical appearance anxiety can develop students mind that being afraid of being judged by their looks and body image is anxiety. If people have anxiety because of their physical appearance may be it can sequel badly in social relations.

Social appearance may be correlated with social anxiety stresses in general pleasing appearance (Hart, Flora, Palyo, Fresco, Holle, \& Heimberg, 2008). Social appearance anxiety in adolescence might have a harmful and serious sequel in upcoming future life (Celik, Turan, $\&$ Arici, 2014). Meanwhile, social appearance anxiety is thought of as one of the parts of the social anxiety (Amil \& Bozgeyiklf, 2015).

In addition, anxiety as a fear or nervousness what might happen (Merriam Webster). People experience anxiety when they become conscious that their existence or some value with it might be destroyed. Meanwhile, they also said that anxiety, like dizziness, can be either delight or painful feeling, positive or negative. It can be either normal or neurotic. No one can get away the sequel of anxiety. It can grow from early stage to old stage, their ethics change, and with each step has normal anxiety encounter. Normal anxiety can be also experienced during those creative moments when a fine artist, a scientist, or a thinker suddenly reach an understanding that leads to a realization that one's life or other lives will be eternally changed. Neurotic anxiety, the type experienced during time of growth or of threat to one's values or moral principle, is experienced by everyone. It can be positive provided it remains correlative to a threat. But anxiety can become neurotic or sick (Feist, Feist, \& Roberts, 2013).

One of the types of anxiety related to the study is normal anxiety. Having a fear of negatively evaluation of physical appearance can change lives of the people because of experiencing of anxiety. Thus, whether it can be normal or neurotic anxiety but having a fear or afraid of being judged because of its looks and body image is an anxiety. In relation to this, the researcher would be assessing the physical appearance anxiety and social relations of the students and the result will be the basis for the study.

\subsection{Statement of Purpose}

The study intends to know the level of physical appearance anxiety and level social relations among senior high school students in a certain senior high school in Mandaue City, Philippines and the association of the two variables.

\section{Review Related Literature}

Physical appearance anxiety is an anxiety which is about being afraid of negatively judged in terms of ones' overall appearance. While, social relations refer to the relationship between two or more people through communications 
Social appearance anxiety was associated with measures and it was significant to predict social anxiety, measure of negative image and downheartedness (Hart, Flora, Palyo, Fresco, Holle, \& Heimberg, 2008). It has also relationship to the levels of loneliness of the adolescents (Amil \& Bozgeyikli, 2015). And was in higher level in dental alignment and gender does not differ in social appearance anxiety (Arnasyali \& Sabuncuoglu, 2017). Social appearance anxiety scale (SAAS) has a positively meaningful relationship in terms of interaction anxiety, fear of negatively judged and behaviors anxiety (Levinsn \& Rodebaugh, 2011). Similarly, it has a connection with social evasion, fear of negatively judged and pain among teenagers in the community (Dakanalis, Carra, Calogero, Zanetti, Volpato, Riva, Clerici, \& Cipresso, 2015). On other conducted study, there was a higher level of scores among disabled athletes participant to self-confidence and social appearance anxiety dissimilar to non-abled athletes' participant (Demirel, 2019). Correspondingly, self-criticism was related to negatively judge since students with obesity had excessive level of self-criticism than the other students who are not obese (Khan \& Naqvi, 2016). As well as study shows that women had higher level of anxiety in related to weight than the men (Vega, Chavez, Rodriguez-Villalobos, Ornelas, \& Lopez, 2014). Fear of negatively judged was positive correlated with body weight among men and women in the measurement of body mass index (BMI) (Trompeter, et al., 2018).Besides among men and women, internalization, ideals body appearance, physical appearance with communication with friends, criticism of friends appearance and body mass index (BMI) has a meaningful relations with body satisfaction (Lawler \& Nixon, 2010). Moreover, social anxiety and symptoms of eating disorders was linked to social appearance anxiety (Levinson, et al., 2013). While masculine students undergo physical appearance anxiety which is concerned image and looks of individual because of the negatively discernment and assessment (Turan, Aydin, Kaya, Aksel, \& Yilmaz, 2019). Negatively judged and social appearance was significant of social negative assessment anxiety in the situation of social anxiety, intake of food and discontentment of individuals' body (Levinson \& Rodebaugh, 2015). And also, it was revealed that binge eating notable predicted to social appearance anxiety, dietary restraint and dealing with mistakes (Brosof \& Levinson, 2017). Likewise, negative body looks has a relationship with apprehension, revulsion, distress, displeasure and timidness (Alijomaa, 2018).

On other hand, social appearance was negatively parallel with information of descriptive of awareness of metacognitive and procedural, preparation, self-control, information of cognitive strategies, self- assessment and self-examine (Celik, Turan, \& Arici, 2014). Selfesteem had no relationship with social appearance anxiety (Sahin, Barut, Ersanli, \& Kumcagiz, 2014).Participants were reduced lower level of anxiety when the body image were low while those with high level of physical appearance anxiety neither elaborated and standard video feedback with no condition of video feedback (Orr \& Moscovitch, 2013). Whereas social appearance anxiety of men and women did not differ in regards to gender (Varol, Erbas, \& Unlu, 2014). And also, no meaningful connection with body mass index (BMI) (Alemdag, Alemdag, \& Ozkara, 2016). As well as, there was no notable relationship between the levels of body image of the participant (Aydin, Evrensel, \& Ceylan, 2017). No remarkable association between dissatisfaction of body image and physical selfconceptualization (Alipoot Moazami- Goodarzi, Nezhad, \& Zaheri, 2009). Body mass index 


\section{MInstitute ${ }^{\text {Mink }}$}

(BMI) was not correlated of physical appearance and fear of negatively judged (FNE) (Ahadzadeh, Rafik- Galea. Alavi, \& Amini. 2018). Moreover, drive for muscularity among men was disparity related with mindfulness and positively connected with body evaluation and satisfaction areas of the body when after the case of the negative sequel and body mass index (BMI) (Lavender, Gratz, \& Anderson, 2012). Levels of social appearance anxiety physical education participants were low (Yuceant \& Unlu, 2017). In addition, social appearance anxiety has no noteworthy associated with the participants and has relationship with negative encouragement (Argon, 2014). In that case, it was also not related with the symptoms of social anxiety (Levinson \& Rodebaugh, 2016). While there was a negatively connection between fear of negative evaluation of music teachers participant in regards to gender and age (Yokus, 2013). And also, body mass index (BMI) does not linked of fear negative appearance evaluation (Lundgren, Anderson, \& Thompson, 2004). Additionally, individuals of body image satisfaction was linked to happiness in terms of physical appearance assessment, overweight pensiveness and ones' body and social relationship was not significant predicted to contentment (Chen, 2015).

In this case, the researchers intend to assess the anxiety of the students in the locality in order to know if it really affects students and necessary measures can be identified.

\section{Research Method}

The study is a brief cross-sectional study of the two identified variables. By complete enumeration, the study was conducted in senior high school with about 244 cases out of 245 Senior High School who are invited.

\subsection{Instrument}

For this study, a rating scale questionnaire is used as a tool to achieve the main objective of the study. The respondents rate each indicator with 1 as Never, 2 as Sometimes and 3 as Always

\subsection{Data Gathering Procedure}

The researcher asked an approval from the school administrator of the school and from the teachers in grades 11 and 12. The purpose of the study was explained as well as its contribution to the field of the study.

The respondents can answer the rating scale questionnaire comprehensively in ten minutes. After gathering all the data, the researchers tabulated the ratings. The results are presented in the proceeding contents

\subsection{Statistical Treatment}

The sum for both level of physical anxiety and level of social relations. 


\section{Macrothink \\ International Journal of Social Science Research \\ ISSN 2327-5510 2020, Vol. 8, No. 1}

\section{Results}

Table 1. Physical appearance anxiety

\begin{tabular}{lll}
\hline Indicators & WM & Interpretation \\
\hline 1. The extent to which I look overweight. & 1.77 & Sometimes \\
2. My thighs. & 1.84 & Sometimes \\
3. My buttocks. & 1.71 & Sometimes \\
4. My hips. & 1.88 & Sometimes \\
5. My stomach. & 2.02 & Sometimes \\
6. My legs. & 1.96 & Sometimes \\
7. My skin. & 1.98 & Sometimes \\
8. My waist. & 1.81 & Sometimes \\
9. My ears. & 1.70 & Sometimes \\
10. My lips. & 1.84 & Sometimes \\
11. My wrist. & 2.01 & Sometimes \\
12. My hands. & 1.89 & Sometimes \\
13. My forehead. & 1.75 & Sometimes \\
14. My height. & 1.94 & Sometimes \\
15. My chin. & 1.72 & Sometimes \\
16. My feet. & 1.80 & Sometimes \\
Overall Weighted Mean & $\mathbf{1 . 8 6}$ & Sometimes \\
\hline
\end{tabular}

LEGEND: 1.00- 1.67 (Never); 1.68- 2.34 (Sometimes); 2.35 - 3.00 (Always)

The table 1 shows the weighted mean of the level of anxiety in terms of physical appearance. The overall weighted mean was 1.86 which is interpreted as sometimes. This result reveals a considerable reason to consider that there have been anxiety experienced by the students which could result to unpleasant emotions. For instance, fear of negatively judged can be associated with body weight among men and women in the measurement of body mass index (Trompeter, et.al, 2018). Sadly, negative body looks has a relationship with apprehension, revulsion, distress, displeasure and timidity (Alijomaa, 2018). 
Table 2. Social Relations

\begin{tabular}{lll}
\hline Indicators & WM & Interpretation \\
\hline 1. I feel comfortable with the way I appear to others. & 2.16 & Sometimes \\
2. I feel nervous when they picture taken. & 1.94 & Sometimes \\
3. I get tense when it is obvious people are looking at me. & 2.25 & Sometimes \\
4. I am concerned people would not like me because of the way I look. & 2.08 & Sometimes \\
5. I worry that others talk about my flaws in my appearance. & 2.06 & Sometimes \\
6. I am concerned people will find me unappealing because of my appearance. & 2.00 & Sometimes \\
7. I worry that my appearance will make life more difficult. & 1.86 & Sometimes \\
8. I am concerned that I have missed out on opportunities because of my appearance. & 1.94 & Sometimes \\
9. I am afraid that people think I am not good looking. & 1.86 & Sometimes \\
10. I am concerned that people think I am not good looking. & 1.84 & Sometimes \\
11. I get nervous when talking to people because of the way I look. & 1.87 & Sometimes \\
12. I feel anxious when other people say something about my appearance. & 1.98 & Sometimes \\
13. I am frequently afraid I would not meet others' standards of how should I look. & 1.89 & Sometimes \\
14. I worry people will judge the way I look negatively. & 1.97 & Sometimes \\
15, I am comfortable when I think others are noticing flaws in my appearance. & 2.07 & Sometimes \\
16. I worry that a romantic partner will/would leave me because of my appearance. & 1.87 & Sometimes \\
Overall Weighted Mean & $\mathbf{1 . 9 8}$ Sometimes
\end{tabular}

LEGEND: 1- 1.67 (Never); 1.68- 2.34 (Sometimes) 2.35 - 3 (Always)

The table 2 shows the level of social relations towards physical appearance anxiety. The overall weighted mean was 1.98 which was interpreted as sometimes. This can indicate that social relations equally exist among the students. "Sometimes" can mean that social relations can be affected with physical appearance anxiety. Social appearance anxiety has a connection with social evasion, fear of negatively judged and pain among teenagers in the community (Dakanalis, et. al, 2015). Among men and women, internalization, ideals body appearance, physical appearance with communication with friends, criticism of friends appearance and body mass index (BMI) has a meaningful relations with body satisfaction Physical appearance anxiety: the extent to which I look overweight and social relations (Lawler and Nixon, 2010). 
Table 3. Association between Physical Appearance Anxiety and Social Relations

\begin{tabular}{lll}
\hline Categories & Value & Asymp. Sig. (2-sided) \\
\hline The extent to which I look overweight and social relations & $1.061 \mathrm{E} 2^{\mathrm{a}}$ & .001 \\
My thighs & $1.000 \mathrm{E} 2^{\mathrm{a}}$ & .003 \\
My buttocks & $1.081 \mathrm{E} 2^{\mathrm{a}}$ & .000 \\
My hips & $1.081 \mathrm{E} 2^{\mathrm{a}}$ & .000 \\
My stomach & $1.098 \mathrm{E} 2^{\mathrm{a}}$ & .000 \\
My legs & $1.135 \mathrm{E} 2^{\mathrm{a}}$ & .000 \\
My skin & $1.200 \mathrm{E} 2^{\mathrm{a}}$ & .000 \\
My waist & $87.899^{\mathrm{a}}$ & .025 \\
My ears & $1.237 \mathrm{E} 2^{\mathrm{a}}$ & .000 \\
My lips & $1.024 \mathrm{E} 2^{\mathrm{a}}$ & .002 \\
My wrists & $1.166 \mathrm{E} 2^{\mathrm{a}}$ & .000 \\
My hands & $1.326 \mathrm{E} 2^{\mathrm{a}}$ & .000 \\
My forehead & $1.175 \mathrm{E} 2^{\mathrm{a}}$ & .000 \\
My height & $1.479 \mathrm{E} 2^{\mathrm{a}}$ & .000 \\
My chin & $96.964^{\mathrm{a}}$ & .005 \\
My feet & $1.606 \mathrm{E} 2^{\mathrm{a}}$ & .000 \\
Df & 64 & \\
$\mathbf{N}$ of Valid Cases & 244 & \\
\hline
\end{tabular}

\section{Discussion}

The table 3 shows the association between physical appearance anxiety and social relations. The computed chi-square $\left(1.061 \mathrm{E} 2^{\mathrm{a}}\right)$ of the two variables which is physical appearance anxiety, specifically in the extent of which I look overweight and Social relations. With the significant level alpha (0.05) is greater than the computed value (.001) This implies that physical appearance anxiety specifically the extent of which I look overweight has association with social relations. Hence, physical appearance anxiety specifically the extent of which I look overweight has effects in terms with social relations. In some particular case, men have more an impact on overweight than women although, the level of the overweight and obesity has remained high in recent years (Schienkiewitz, Mensink, \& Kuhnert, 2017). In addition, pre- and primary of young girls and boys who are overweight and obese are distinctly possible to continue to be a fat as a teenagers and adults. Thus, the overweight has a connection to poor health which the risk was increased (William \& Greene, 2018).Generally, overweight has an impact to men and women which can result that overweight influence to social relations of men and women.

Physical appearance specifically my thighs and social relations shows that the thighs of senior high school students are significant to social relations. The significant level alpha (0.05) is greater than the significant value (.003). As a result, it rejects the null hypothesis. In that case, physical appearance anxiety specifically the thighs has an impact in regards with social relations. Based on medical records, smaller thigh circumference was correlated with diabetes 
(Jung, Yun, \& Jee, 2013). Overall, thighs have an effect of men and women which can also impact to social relations.

Physical appearance anxiety specifically my buttocks and social relations show that buttocks among senior high school students are significant to social relations which the computed value (.000) less than the alpha (0.05). This implies that physical appearance anxiety specifically the buttocks has association with social relations. Similarly, buttocks are not significant to attractiveness (Furnham \& Swami, 2007). However, buttocks do play a main significant in physical and attractiveness in sexuality (Cuzalina \& Retana, 2019).

Physical appearance anxiety specifically my hips and social relations shows that the hips of Senior High School students particularly grade 11 and 12 students are significant to social relations as evident in the significant level alpha $(0.05)$ which is greater than the p-value (.000). In other words, his implies that physical appearance anxiety specifically the hips of grade 11 and 12 Senior High School students has meaningful association with social relations. In addition, there was a significant meaningful relationship of young boys and girls and Waist-to-Hip Ratio (WHR) (Buttovskaya, Sorokowska, Karwowski, Sabinlexicz, Fedenok, Dronova, Negasheva, Selivanova, \& Sorokowski, 2017). While, men preferred woman having low of Waist-to-Hip Ratio (WHR) values below average of different forms of trait (Koscinski, 2014).

In terms of "my stomach" and "social relations", the table above shows that stomach of grade 11 and 12 Senior High School students are significant to social relations in which the p-value(.000) less than the significant alpha at 0.05 . In overall, physical appearance anxiety specifically the stomach of grade 11 and 12 senior high school students has an influence in terms with social relations. Moreover, study shows that women had higher level of anxiety in related to weight than the men which the men tend to more anxious of their beauty in physical (Vega, Chavez, Rodriguez-Villalobos, Ornelas, \& Lopez, 2014). And body mass index (BMI) was not correlated of physical appearance and fear of negatively judge (FNE) (Ahadzadeh, Rafik- Galea, Alavi, \& Amini, 2018).

In terms of "the legs" and "social relations", the table revealed that that the legs of Senior High School students particularly grade 11 and 12 students are significant to social relations in which the alpha (0.05) is greater than the p-value (.001).. Thus, the length of the legs that has a connection of individuals' body can influence perceived attractiveness and females tend to inclined to longer legs, as evaluated among by men and women (Bertamini \& Bennett, 2009). Moreover, across all the nations, male and female silhouettes with short and long legs were perceived and likely less appealing. Hence too long legs were more appealing compared to too short legs (Sorokowski, et al., 2011). Furthermore, physical appearance specifically hips have affects to men and women which can influence to social relations.

The table above revealed that the "skin" particularly grade 11 and 12 students are significant to social relations in which the p-value (.000) is lesser than the significant alpha (0.05). Thus, physical appearance anxiety specifically the skin has positively relationship in terms with social relations. Furthermore, the color of the skin cause the ratings of the attractiveness which the black people with light colored skin and white people with darker colored skin 
were assessed more appealing (Hersch, 2011). More appealing individual were more inclined to be connected with characteristics which is positive. Hence, less appealing of individuals are more inclined to be associated with negative ones (Frisby, 2006).Generally, physical appearance specifically the skin have an impact to both men and women with their social relations.

The waist among grade 11 and 12 senior high school students are significant to social relations with computed value (.025) lesser than the significant alpha (0.05). As said, physical appearance anxiety specifically the waist has a meaningful relationship in terms with social relations. Additionally, women tend to prefer to lower in Waist-to-Hip Ratio (WHR) compared to men, which recommend that women prefer to small waist rather than the hips in contrast with men (Koscinski, 2013). Men with low Waist-to-Hip Ratio and Body Mass Index (BMI) were most appealing in populations of well-nourish that shows fertility (Lassek \& Gaulin, 2018). In that case, waist has an impact of men and women which the waists of grade 11 and 12 students influence their social relations.

Ears of the students are significant to social relations as evident in significant alpha (0.05) is greater than the p-value (.000). This is true especially with having a disease on ears which can lead to anxiety has an influence to both men and women. Generally, this could happen to the ears of the students which affects social relations.

Lips can be associated to social relations as indicated in the p-value (.002) lesser than the alpha (0.05). Additionally, the lightness of facial skin becomes lighter when it was perceived made of lips that were more color red and the darker colored lips made it darker (Kobayashi, Matsushita, \& Morikawa, 2017). Fuller lips had been considered more appealing compared to thin flat lips in traditional. Hence, sense of youth, health and appealing has been shown when the lips are full and well- silhouette (Trookman, Rizer, Foed, Mehta, Gotz, \& Pharm, 2007). Generally, lips have an affects among both sexes men and women which can influence in terms of social relations.

Wrists of 11 and 12 students can be associated to social relations. As displayed, the p-value (.000) is lesser than the significant level alpha (0.05). Unknowingly, wrists can be used to approximate the age of the person in which many of the senior high schools therein are old enough to be in the senior high school. As said, when left hand wrist was developing maturely, it was view as an archetypal of individual which it can be use in estimation of age and has been studied extensively (Dogaroiu, Hackman, Gherghe, Panaitescu, \& Avramoui, 2013).In that case, having an anxiety in physical appearance specifically wrists has an impact to adolescents. Hence, wrists have an influence to social relations.

Hands are significant to social relations. The alpha (0.05) is greater than the p-value (.000). Additionally, attractiveness of hands of opposite sex were become conscious among men and women in a not random manner and most of them were more tend to prefer of average of shape, femininity, long fingers and skin which is smooth (Koscinski, 2011). In some particular cases, a student's social relations can be affected with pathologic and therapized hand. Hand appearance evaluation can show the effects of pathology of hand and the therapeutic interventions effectiveness (Johnson, Sebastian, Rehim, \& Chung, 2015). 


\section{Al Macrothink}

International Journal of Social Science Research

ISSN 2327-5510

2020, Vol. 8, No. 1

Therefore, physical appearance anxiety specifically the hands have a notable effect in regards with social relations of adolescents.

Significant alpha (0.05) is greater than the p-value (.000). This implies that physical appearance anxiety specifically the forehead has positive association with social relations. On other hand, straight necks and foreheads of individuals' profile were scored as the most appealing profile (Oshagh, Aleyasin, \& Roeinpeikar, 2012). Foreheads would be unique as in contrast from one another in the existence and the size and shape of pattern of wrinkles that they carry (Alfadaly, 2015). Overall, physical appearance anxiety specifically the forehead has an impact in terms with social relations.

The significant level alpha (0.05) is greater than the computed value (.000). It means that height has association with social relations. Similarly at work, physical height has an impact of career of the people and interactions in their workplace (Judge \& Cable. 2004). Hence, men are viewed as more leader than compared to women and tall participants were viewed as more leader compared to short participants (Blaker, Rompa, Dessin, Vriend, Herschberg, \& Vugt, 2012). Furthermore, physical appearance anxiety specifically the height has an influence in regards with social relations.

Physical appearance anxiety specifically the chin has an association in regards with social relations since p-value (.005) less than the significant level alpha (0.05). When anxiety becomes more prevailing, people who can afford would prefer to go under surgical improvement. Moreover, treatments were seek of participants to treat their discontent in their double chins (Bhojwani, 2016). In the first place, the shape of the chin was not a universal in the sense of strict because there were a notable disparity between regions of geographic of men and women (Thayer \& Dobson, 2013). Hence, physical appearance anxiety specifically the chin has an influence in terms with social relations.

Physical appearance anxiety specifically my feet and social relations are associated as indicated in the result that significant level alpha (0.05) is greater than the p-value (.000). In some particular cases, small feet were contributed to the attractiveness of the females while men with average size of feet were thinks as the most appealing (Fessler, et al., 2005). Therefore, physical appearance anxiety specifically the feet have and affect with social relations of men and women.

\section{Conclusion}

Students who are afraid of being judged negatively are experience of physical appearance anxiety. It shows that the levels of physical appearance anxiety of grade 11 and 12 Senior High School students were interpreted as Sometimes which means that physical appearance anxiety impact on students. And the levels of social relations were interpreted as Sometimes which means that the social relations impacts on students This implies that these physical appearance anxiety and social relations are significant which was based on the result of computation of chi- square. It has been manifested that physical appearance anxiety has a significant association with social relations. Furthermore, whatever the effects of social relations are based on anxiety in terms of individuals physical appearance. 


\section{References}

Ahadzadeh, A. S., Rafik-Galea, S., Alavi, M., \& Amini, M. (2018). Relationship between body mass index, body image, and fear or negative evaluation: moderating role of selfesteem. Health Psychology Open, 5-8. https://doi.org/10.1177/2055102918774251

Alemdag, S., Alemdag, C., \& Ozkara, A.B. (2016). Social appearance anxiety of fitness participants. Baltic Journal of Sport \& Health Sciences, 3(102), 4-7, https://doi.org/10.33607/bjshs.v3i102.58

Alfadaly, N. (2015). Forehead morphology pattern: does it indicate the potential of the so-called forehead print? International Journal of Forensic and Pathology (IJFP), 3(10), 188-189. https://doi.org/10.19070/2332-287X-1500044

Alipoor, S., Moazami-Goodarzi, A., Nezhad, M. Z., \& Zaheri, L. (2009). Analysis of the relationship physical self-concept and body image dissatisfaction in female students. Journal of Social Sciences, 5(1), 63-64. https://doi.org/10.3844/jssp.2009.60.66

Aljomaa, S. S. (2018). The relationship between body image satisfaction and bulimia nervosa among king saud university students. International Education Studies, 11(5), 129-130. https://doi.org/10.5539/ies.v11n5p123

Amasyali, M., \& Sabuncuoglu, F. A. (2017) Level of Social Appearance in Individuals with and without Alignment of Teeth. Turkish Journal of Orthodontics, 5. https://doi.org/10.5152/TurkJOrthod.2017.1622

Amil, O., \& Bozgeyikli, H. (2015). Investigating the relationship between the social appearance anxiety and loneliness of turkish university youth. Journal of Studies in Social Sciences, 11(1), 71-91. Retrieved from: https://www.researchgate.net/publication/304349739_Investigating_the_Relationship_betwee n_Social_Appearance_Anxiety_and_Loneliness_of_Turkish_University_Youth

Argon, T. (2014). The relationship between social appearance anxiety and motivational resources and problems of education faculty students. The Anthropologist, 18(3), 5-8. https://doi.org/10.1080/09720073.2014.11891600

Aydin, Y., Evrensel, A., \& Ceylan, M. E. (2017). Body image, self- esteem and social anxiety levels in individuals with alcohol and substance abuse. Medicine Science International Journal, 4-5, https://doi.org/10.5455/medscience.2017.06.8740

Bertamini, M., \& Bennett, K. T. (2009). The effect of leg length n perceived attractiveness $\mathrm{f}$ simplified stimuli. Journal of Social, Evolutionary, and Cultural Psychology, 3(3), 247-250. https://doi.org/10.1037/h0099320

Bhojwani, A. (2016). Addressing the "double chin": trends in submental contouring. Journal of Dermatology and Cosmetology, 1(1), 2-3. https://doi.org/10.15406/jdc.2016.01.00002

Blaker, N. M., Rompa, I., Dessing, I. H., Vriend, A. F., Herschberg, C., \& Vugt, M. V. (2012). The height leadership advantage in men and women: testing evolutionary psychology 
predictions about the perceptions of tall leaders (pp. 7-12). Retrieved from https://www.researchgate.net/publication/258137980_The_height_leadership_advantage_in_ men_and_women_Testing_evolutionary_psychology_predictions_about_the_perceptions_of_ tall_leaders/link/54bbe0900cf29e0cb04be2d8/download

Brosof, L. C., \& Levinson, C. A. (2017). Social appearance anxiety and dietary restraint as mediators between perfectionism and binge eating: a six-month three wave longitudinal study. Appetite, 108, 335-342. https://doi.org/10.1016/j.appet.2016.10.015

Butovskaya, M., Sorokowska, A., Karwowski, M., Sabniewicz, A., Fedenok, J., Dronova, D., ... Sorokowski, P. (2017). Waist-to-hip ratio, body=mass index, age and number of children in seven traditional societies. Scientific Reports, 8-9. https://doi.org/10.1038/s41598-017-01916-9

Celik, E., Turan, M. E., \& Arici, N. (2014). The role of social appearance anxiety in metacognitive awareness of adolescents. International Journal of Learniing, Teaching and
Educational
Research,
$7(1)$
144-147.
Retrieved
from

https://www.researchgate.net/publication/289910569_The_Role_of_Social_Appearance_Anx iety_in_Metacognitive_Awareness_of_Adolescents

Chen, M. J. (2015). The association of body image and interpersonal relationships as it relates to happiness (pp. 17-21). Retrieved from: https://stars.library.ucf.edu/cgi/viewcontent.cgi?referer=https://www.google.com/\&httpsredir $=1 \&$ article $=2858 \&$ context $=$ honorstheses $1990-2015$

Cuzalina, A., \& Retana, A. (2019). Creating the ideal buttock (lifting, implanting or fat grafting) (pp. 1-2). https://doi.org/10.5772/intechopen.84660

Dakanalis, A., Carra, G., Calogero, R., Zanetti, A. M., Volpato, C., Riva, G., Clerici, M., \& Cipresso, P. (n.d.). The Social Appearance Anxiety Scale in Italian Adolescent Populations: Construct Validation and Group discrimination in Community and Clinical Eating Disorders Samples (pp. 13-18).

Demirel, H. (2019). Social appearance anxiety and rosenberg self- esteem scores in young physical disabled athletes. Universal Journal of Educational Research, 7(3). https://doi.org/10.13189/ujer.2019.070304

Dogaroiu, C., Hackman, L., Ghenghe, E., Panaitescu, E., \& Avramoiu, M. (2013). Value of the appearance of the left-hand wrist ossification centres to age estimation in Roma population. RJLM, 2(4), 299-304. https://doi.org/10.4323/rjlm.2013.299

Fessler, D. M., Nettle, D., Afshar, Y., Oinheiro, D. A., Bolyanatz, A., Mulder, M. B., ... Zbarauskaite, A. (2005). A cross-cultural investigation of the ol of foot size in physical attractiveness. Archives of Sexual Behavior, 34(3), 274-275. https://doi.org/10.1007/s10508-005-3115-9

Feist, J., Feist, G. J., \& Roberts, T. A. (2013). Theories of Personality (8th ed., pp. 325-327). Americas, New York. 
Frisby, C. (2006). Shades of beauty: examining the relationship of skin color to perceptions of physical attractiveness (pp. 11-14). Retrieved from: https://www.researchgate.net/publication/220427986_The_Appearance_of_Human_Skin/link /0912f511980fe8490c000000/download

Furnham, A., \& Swami, V. (2007). Perception of female buttocks and breast size in profile. Social Behavior and Personality, 35(1), 4-5. https://doi.org/10.2224/sbp.2007.35.1.1

Hart, T. A., Flora, D. B., Fresco, D. M., Holle, C., \& Heimberg, R. G. (2008). Development and examination of the social appearance anxiety scale. Assessment, 15(1), 49-56. https://doi.org/10.1177/1073191107306673

Heitmann, B. T. (2009). Thigh circumference and risk of heart disease and premature death: prospective cohort study (pp. 5-8). https://doi.org/10.1136/bmj.b3292

Hersch, J. (2011). Skin color, physical appearance, and perceived discriminatory treatment (pp. 11-26). https://doi.org/10.2139/ssrn.1857160

Johnson, S. P., Sebastian, S. J., Rehim, S. A., \& Chung, K. C. (2015). The importance of hand appearance as a patient's reported outcome in hand surgery. Plastic and Reconstructive Surgery - Global Open, 3(11), 9-10. https://doi.org/10.1097/GOX.0000000000000550

Judge, T. A., \& Cable, D. M. (2004). The effects of physical height on workplace success and income preliminary test of a theoretical model. Journal of Applied Psychology, 89(3), 439-441. https://doi.org/10.1037/0021-9010.89.3.428

Jung, K. J., Kimm, H., Yun, J. E., \& Jee, S. H. (2013). Thigh circumference and diabetes: obesity as a potential effect modifier (pp. 333-334). https://doi.org/10.2188/jea.JE20120174

Khan, S. K., \& Naqvi, I. (2016). Self- criticism and fear negative evaluation among university students with and without obesity. Pakistan Journal of Psychological research, 31(2), 522-530. Retrieved from http://citeseerx.ist.psu.edu/viewdoc/download?doi=10.1.1.853.7526\&rep=rep1\&type=pdf

Kobayashi, Y., Matsushita, S., \& Morikawa, K. (2017). Effects of lip olor on perceived lightness of human facial skin (pp. 6-7). Retrieved from https://www.researchgate.net/publication/318678794_Effects_of_Lip_Color_on_Perceived_L ightness_of_Human_Facial_Skin/link/597758c7aca27203ecbdd64d/download

Koscinski, K. (2011). Determinants of hand attractiveness-a study involving digitally manipulated stimuli (pp. 692-693). https://doi.org/10.1068/p6960

Koscinski, K. (2013). Assessment of waist-to-hip ratio attractiveness in women: an anthropometric analysis of digital silhouettes (pp. 395-396).

Koscinski, K. (2013a). Attractiveness of women's body: body mass index, waist-hip ration, and their relative importance (pp. 8-12). Retrieved from https://www.researchgate.net/publication/264469986_Attractiveness_of_women's_body_Bod y_mass_index_waist-hip_ratio_and_their_relative_importance/link/5675b9c308aebcdda0e46 
e01/download

Lassek, W. D., \& Gaulin, S. T. C. (2018). Do the low whrs and bmis judged most attractive indicate higher fertility? Evolutionary Psychology, 5-16. https://doi.org/10.1177/1474704918800063

Lavender, J. M., Gratz, K. M., \& Anderson, D. A. (2012). Mindfulness, body image, and drive for muscularity in men. Body Image, 9(2), 291-292. https://doi.org/10.1016/j.bodyim.2011.12.002

Lawler, M., \& Nixon, E. (2010). Body dissatisfaction among adolescent boys and girl: the effects of body mass, peer appearance culture and internalization of appearance ideals. $J$ Youth Adolesc., 40(1), 59-71. Retrieved from https://www.ncbi.nlm.nih.gov/pubmed/20058058

Levinson, C. A., \& Rodebaugh, T. L. (2011) Validation of the Social Appearance Anxiety Scale: Factor, Convergent, and Divergent Validity. Assessment, 18(3), 5-6, https://doi.org/10.1177/1073191111404808

Levinson, C.A., and Rodebaugh, T.L. (2016). Clarifying the prospective relationships between social anxiety and eating disorder symptoms and underlying vulnerabilities. Appetite, 107, 38-46. https://doi.org/10.1016/j.appet.2016.07.024

Levinson, C. A., \& Rodebaugh, T. L. (2015). Negative social evaluative fears produce social anxiety, food intake, and body dissatisfaction: evidence of similar mechanisms through different pathways. Clinical Psychological Science, 3(5), 12-23. https://doi.org/10.1177/2167702614548891

Levinson, C. A., Rodebaugh, T. L., White, E. K., Menatti, A., Weeks, J. W., Iacovino, J. M., \& Warren, C. S. (2013). Social appearance anxiety, perfectionism, and fear of negative evaluation: distinct or shared risk factors for social anxiety and eating disorders? Appetite, 67, 125-133. https://doi.org/10.1016/j.appet.2013.04.002

Lundgren, J. D., Anderson, D. A., \& Thompson, J. K. (2003). Fear or negative appearance evaluation: development and evaluation of a new construct for risk factor work in the field of $\begin{array}{lllll}\text { eating disorders. } & \text { Eating } & \text { Behaviors, }\end{array}$ https://doi.org/10.1016/S1471-0153(03)00055-2

Orr, E. M. J., \& Moscovitch, D. A. (2013). Physical appearance anxiety impedes the therapeutic effects of video feedback in high socially anxious individuals. Behavioral and Cognitive Psychotherapy, 8-9.

Oshagh, M., Aleyasin, Z. S., \& Roeinpeikar, M. (2012). The effects of forehead and neck positions on profile esthetics. European journal of esthetic dentistry: official journal of the European Academy of Esthetic Dentistry, 7(4), 454-466. Retrieved from: https://www.researchgate.net/publication/233412438_The_effects_of_forehead_and_neck_po sitions_on_profile_esthetics/link/0046352bd8f9d71346000000/download

Sahin, E., Barut, Y., Ersanli, E., \& Kumeagiz, H. (2014). Self-esteem and social appearance 
anxiety: an investigation of secondary school students. Journal of Basic and Applied Scientific Research, 4(3), 156-157. Retrieved from https://files.eric.ed.gov/fulltext/ED559714.pdf

Schienkiewits, A., Mensink, G. B. M., Kuhnert, R., \& Lange, C. (2017). Overweight and obesity among adults in Germany. Journal of Health Monitoring, 22-23.

Sorokowski et al. (2011). Attractiveness of leg length: report from 27 nations. Journal of Cross-Cultural Psychology, 137-138. Retrieved from https://www.researchgate.net/publication/253953054_Attractiveness_of_Leg_Length_Report _From_27_Nations/link/0046351fac0ce6f392000000/download

Thayer, Z. M., \& Dobson, S. D. (2013). Geographic variation in chin shape challenges the universal facial attractiveness hypothesis. PLOS, 3-5. https://doi.org/10.1371/journal.pone.0060681

Trompeter, N. B., Hay, P., Mond, M., Lonergan, A., Griffiths., P., \& Mitchison, D. (2019). Fear of negative evaluation and weight/shape concerns among adolescents: the moderating effects of gender and weight and status. Journal of Youth and Adolescence, 9-11. Retrieved from https://www.ncbi.nlm.nih.gov/pubmed/29845441

Trookman, N. S., Rizer, R. L., Ford, R., Mehta, R., \& Gotz, V. (2009). Clinical assessment of a combination lip treatment to restore moisturization and fullness. The Journal of Clinical Aesthetic, 2(12), 4-5. Retrieved from https://www.ncbi.nlm.nih.gov/pmc/articles/PMC2923945/pdf/jcad_2_12_44.pdf

Turan, N., Aydin, G. O., Kaya, H., Aksel, \& Yilmaz, A. (2019). Male nursing students' social appearance anxiety and their coping attitudes. American Journal of Men's Health, 13(1), 6-13. https://doi.org/10.1177/1557988319825922

Varol, Y. K., Erbas, M. K., \& Unlu, H. (2014). The relationship between social appearance anxiety of adolescents and their attitude toward physical education lesson. Nigde University Journal of Physical Education and Sport Sciences, 8(1), 6-10. Retrieved from: https://www.researchgate.net/publication/299409501_the_relationship_between_social_appea rance_anxiety_of_adolescents_and_their_attitude_toward_physical_education_lesson_ergenl erin_sosyal_gorunus_kaygilari_ile_beden_egitimi_dersine_yonelik_tutumlari_ar

Vega, H. M., Chavez, F. A., Rodriguez-Villalobos, M., Ornelas, J. R. B., \& Lopez, H. L. M. (2014). Body image anxiety on university students (differences men and women). Open Journal of Medical Psychology, 3, 352-353. https://doi.org/10.4236/ojmp.2014.35036

Wlliams, S. E., \& Greene, J. L. (2018). Childhood overweight and obesity: affecting factors, education and interventions. Journal of Childhood Obesity, 3(2:9), 2-7. https://doi.org/10.21767/2572-5394.100049

Yokus, H. (2013). Investigation of relationship between the fear of negative evaluation and musical instrument achievements of music teacher candidates (gaziosmanpaşa university sampling. International Journal of New Trends in Arts, Sports \& Science Education, 2(3), 
https://pdfs.semanticscholar.org/3cfb/7a32a0c242634c70bc4465933a69ae850a8f.pdf?_ga=2. 266948174.1985607329.1578374526-1445940915.1570340065

Yuceant, M., \& Unlu, H. (2017). The analysis of social appearance anxiety levels of physical education teacher candidates in terms of different variables. Turkish Journal of Sport and Exercise, 19(1), 105-108. Retrieved from https://pdfs.semanticscholar.org/5917/f25dc1959e77564ae7b6bccc1da7d6b52080.pdf

\section{Glossary}

Anxiety: the fear or nervousness about what might happen (Merriam Webster).

Physical appearance refers to the looks of senior high school students such as their face, hair, nose, color of the skin, height, legs, body weight height.

Physical appearance anxiety is being afraid of negatively evaluated by other senior high school students of their body image and looks.

Social relations refer to the relationship between two or more Senior High School students through communications.

\section{Appendix}

Appendix 1. Survey Questionnaire for Physical appearance anxiety and Social relations

Name: Grade and Section:

Age: Gender:

Direction: Please read each statement and put a check in the box of your answer. The statements listed below are to be use to describe how anxious, tense, or nervous you feel in general (i.e., usually) about your body or parts of your body and also the attitudes towards social relations.
Legend:
3 - Always
2 - Sometimes
$1-$ Never

\section{Part 1:}

\begin{tabular}{lllll}
\hline Indicator to Physical Anxiety & $\mathbf{3}$ & $\mathbf{2}$ & $\mathbf{1}$ \\
\hline 1. The extent to which I look overweight. & & & \\
2. My thighs & & & \\
3. My buttocks & & & \\
4. My hips & & & \\
5. My stomach \\
6. My legs \\
7. My skin \\
8. My waist \\
9. My ears \\
10. My lips
\end{tabular}


11. My wrists

12. My hands

13. My forehead

14. My height

15. My chin

16. My feet

Adapted from (Hart, Flora, Palyo, Fresco, Holle, \& Heimberg, 2008). DOI: $10.1177 / 1073191107306673$

\section{Part II.}

Indicators

1. I feel comfortable with the way I appear to others.

2. I feel nervous when they picture taken.

3. I get tense when it is obvious people are looking at me.

4. I am concerned people would not like me because of the way I look.

5. I worry that others talk about flaws in my appearance.

6. I am concerned people will find me unappealing because of my appearance.

7. I worry that my appearance will make life more difficult.

8. I am concerned that I have missed out on opportunities because of my appearance.

9. I am afraid that people find me unattractive.

10. I am concerned that people think I am not good looking.

11. I get nervous when talking to people because of the way I look.

12. I feel anxious when other people say something about my appearance.

13. I am frequently afraid I would not meet others' standards of how should I look.

14. I worry people will judge the way I look negatively.

15. I am comfortable when I think others are noticing flaws in my appearance.

16. I worry that a romantic partner will/would leave me because of my appearance.

Retrieved

from:

https://sites.google.com/site/bodyimageresearchgroup/measures/physical-appearance-state-an d-trait-anxiety-scale---state-and-trait-versions-pastas

\section{Copyright Disclaimer}

Copyright for this article is retained by the author(s), with first publication rights granted to the journal.

This is an open-access article distributed under the terms and conditions of the Creative Commons Attribution license (http://creativecommons.org/licenses/by/4.0/). 